\title{
DEL RIEL AL PAVIMENTO: LA MATERIALIZACIÓN DE UNA DISPUTA EN EL LITORAL ARGENTINO ${ }^{1}$
}

\author{
From rail to pavement: materialization of a dispute in the argentine Littoral
}

\author{
Estefanía Szupiany* \\ https://orcid.org/0000-0002-5571-7485
}

\section{Resumen}

A comienzos del siglo XX, el camino pavimentado fue ideado como un medio complementario del sistema ferroviario; sin embargo -lejos de concretarse en tal sentido- la vialidad se convirtió en un peligro y en una amenaza para los trenes argentinos. Esta disputa, junto a la emergencia del sistema automotor, derivó en una serie de transformaciones que se materializaron en el territorio nacional y, de un modo particular, en las ciudades del Litoral argentino. En el entorno fluvial de la ciudad de Santa Fe dicha disputa se tradujo en un proceso de sustitución de infraestructuras de conexión a lo largo del Río Paraná -y sus afluentes- y el Río Salado. En efecto, mientras los puentes ferroviarios sufrían el impacto de las crecidas, los nexos viales emergían como "símbolos de progreso" en el marco del trazado de las primeras rutas nacionales. Rutas que se extendían, por cierto, paralelas a los rieles. Con el objetivo de examinar este proceso de sustitución las fuentes utilizadas corresponden a crónicas periodísticas, a artículos de opinión y divulgación, y a estudios especializados en historia de la movilidad y el transporte como así también de la historia urbana local.

$<$ Ciudades Litorales $><$ Infraestructura Ferroviaria $><$ Infraestructura Vial $><$ Sustituciones $>$

\begin{abstract}
At the beginning of the twentieth century, paved road was conceived as a complementary means to the railway system. Nevertheless, far from becoming an ally, the road became a danger and a threat to Argentine trains. This dispute, combined with the emergence of the automotive system, led to a series of transformations in the national territory and, in particular, in the cities of the Argentine Littoral. In the fluvial environment of Santa Fe city, this dispute gave rise to a process of substitution of infrastructure connections along the Paraná River -and its tributaries- and also along the Salado River. In fact, while railway bridges suffered the impact of flooding, road connections emerged as "symbols of progress" in the context of the development of the first national routes, which, incidentally, extended parallel to the rails. In order to examine this process, various sources are employed: journalistic chronicles, opinion articles, and specialized studies in the history of mobility and transport, as well as local urban history.
\end{abstract}

$<$ Littoral Cities $><$ Railway Infrastructure $><$ Road Infrastructure $><$ Substitutions $>$

Recibido: 18/12/2019 // Aceptado: 19/03/2020

${ }^{1}$ El presente artículo se enmarca en la tesis doctoral de la autora titulada: "La traza y la mancha. Los corredores viales en los procesos de expansión y complejización de la estructura urbana de la ciudad de Santa Fe", defendida en el mes de marzo de 2019 en la FAPyD-UNR.

* Instituto de Humanidades y Ciencias Sociales del Litoral (IHUCSO UNL), Becaria Postdoctoral, Consejo Nacional de Investigaciones Científicas y Técnicas (CONICET). Facultad de Arquitectura, Diseño y Urbanismo, Universidad Nacional del Litoral (UNL), Argentina, eszupiany@gmail.com 
Szupiany. Del riel al pavimento: la materialización de una disputa en el Litoral argentino.

\section{Introducción}

Durante el ciclo de expansión de los ferrocarriles en Argentina, aproximadamente, entre 1880 y 1930, la obra caminera fue concebida en el marco de un sistema complementario de movilidad. La incapacidad de los ferrocarriles para llegar a todos los centros de producción fue resuelta con la incorporación de una nueva tecnología que, desde 1910, había comenzado a ser utilizada en otras regiones del mundo: el motor a explosión en vehículos para el transporte. No obstante, la interacción entre ambos sistemas, lejos de concretarse en un círculo virtuoso, derivó en la paulatina descomposición de la red ferroviaria nacional y, al mismo tiempo, en la proliferación de la obra vial. En este escenario, la sanción de la Ley Nacional de Vialidad $\mathrm{N}^{\circ} 11.658$, el 5 de octubre del año 1932, inauguró el ciclo de la legislación vial argentina —extendido hasta $1946^{2}$ - dando inicio a la ejecución de las obras viales más importantes del país (Boletín de la Dirección General de Investigaciones, Estadísticas y Censos, 1948). Entre ambos ciclos, por lo tanto, se despliega el período de estudio aquí abordado, precisamente, entre las décadas de 1880 y 1940.

Dicha disputa, y la consecuente transición entre ambos sistemas de movilidad, desencadenó una serie de transformaciones —urbanas, regionales y territorialesque se materializaron en el ámbito nacional y, de un modo particular, en las ciudades del Litoral. Entre ellas, la ciudad de Santa Fe (capital de la provincia homónima ubicada en la región Centro-Este de la República Argentina), junto a su área de expansión, se emplaza sobre el sistema fluvial del Río Paraná, precisamente, rodeada por los cursos naturales de la Laguna Setúbal y el Río Salado. En los diversos intentos por conectar a la ciudad y a la región con el territorio circundante, la disputa entre el riel y el pavimento se hizo eco en la construcción de sucesivos puentes, cinco ferroviarios y cuatro viales, a lo largo de un proceso de sustitución de infraestructuras muy alejado de posibles complementaciones. Asimismo, cabe mencionar que estas conexiones asumieron dos direccionalidades dominantes: por un lado, cruzando la Laguna Setúbal, hacia el este de la ciudad de Santa Fe —en vinculación con los pueblos del "Corredor de la Costa"3 — ; por otro lado, atravesando el Río Salado y "El Paso de Santo Tomé"4, hacia el oeste y el sur. De allí, que la delimitación territorial del caso de estudio propuesto corresponde al entorno fluvial comprendido entre la ciudad de Santa Fe y dos de sus localidades aledañas, precisamente, las ciudades de Santo Tomé y San José del Rincón (Figura 1).

2 Tras el golpe de Estado de 1943, la Dirección Nacional de Vialidad fue intervenida. Con la pérdida de su autonomía y el deterioro de su organización interna, se vieron interrumpidas muchas de las obras que venían llevándose a cabo.

3 A partir de un enfoque territorial, Adriana Collado et al. (2012) denominan "Corredor de la Costa" a la unidad geográfica y cultural comprendida entre el barrio de La Guardia y la ciudad de Reconquista, aproximadamente unos $300 \mathrm{~km}$. a lo largo de la Ruta Provincial No 1.

4 La ciudad de Santo Tomé fue originalmente conocida como "El Paso", dado que se formó a partir del cruce obligado para acceder a los caminos de Córdoba - hacia el oeste- y Buenos Aires -hacia el surdesde la ciudad de Santa Fe, en una de las zonas más favorables para vadear el Río Salado. 
Figura 1. Delimitación territorial del caso de estudio: entorno fluvial comprendido entre la ciudad de Santa Fe y las ciudades de Santo Tomé y San José del Rincón

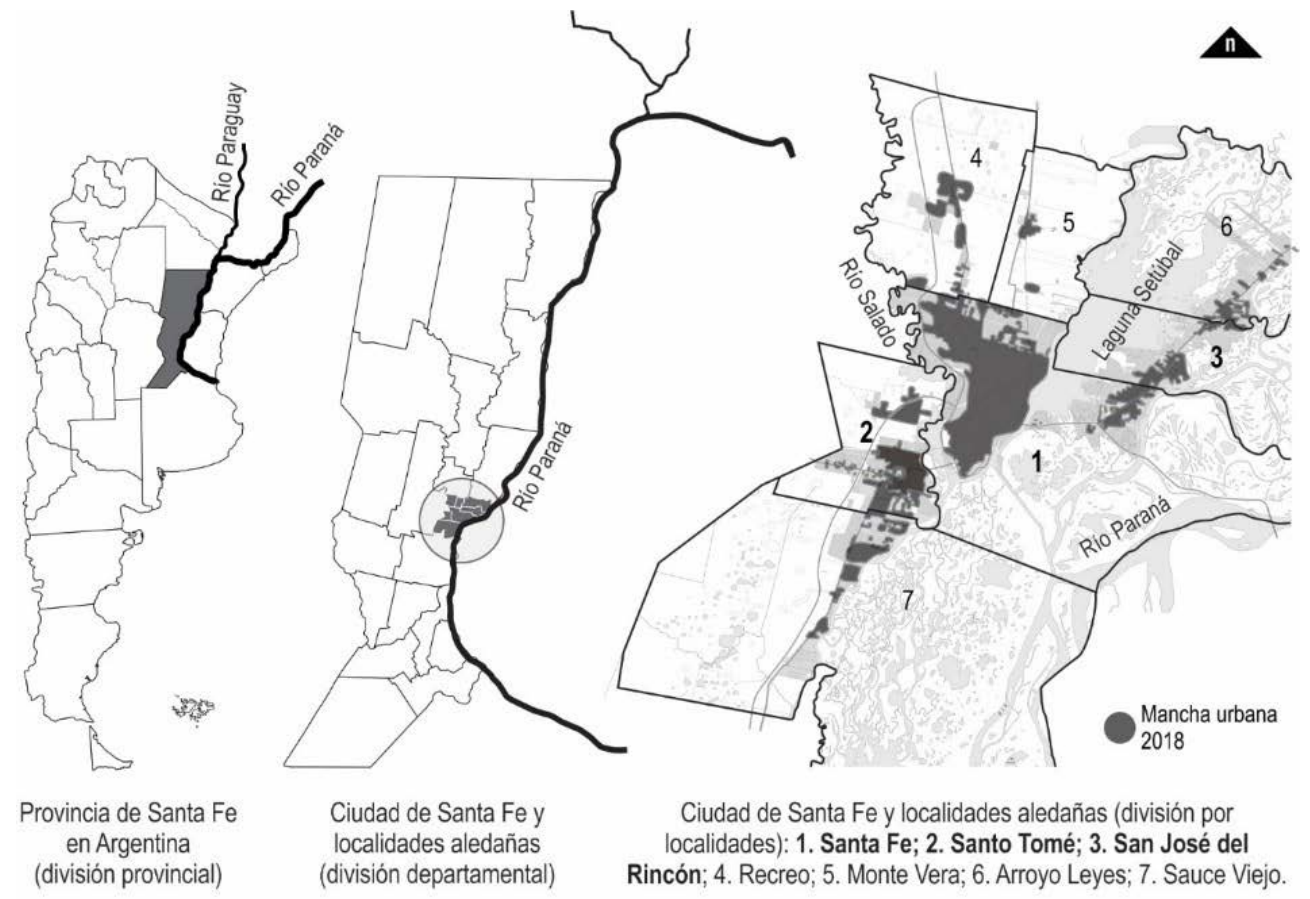

Fuente: Elaboración propia

A partir de esta contextualización, los interrogantes que guiaron la elaboración del presente trabajo fueron los siguientes: ¿Cómo se materializó el proceso de sustitución del sistema ferroviario por el sistema vial en el entorno fluvial comprendido entre las ciudades de Santa Fe, Santo Tomé y San José del Rincón? ¿Cuáles fueron los episodios más relevantes -acontecidos entre las décadas de 1880 y 1940 - que marcaron momentos de inflexión en la movilidad urbana y territorial de la ciudad de Santa Fe y su área de expansión? Para dar respuestas a estas preguntas, el objetivo aquí propuesto consiste en examinar dicho proceso de sustitución entre ambos sistemas de movilidad, a fin de comprender el modo en el que aquella disputa, evidenciada en el ámbito nacional, se materializó en la escena urbana local. Asimismo, se intenta poner en valor los hechos más destacados que impactaron en la definición de las infraestructuras de conexión material sobre el entorno fluvial de la ciudad de Santa Fe y sus localidades aledañas.

A continuación, luego de exponer una breve crónica de esta contienda en el ámbito nacional, se analiza, por un lado, el período de consolidación del modelo agroexportador, en el que la ciudad de Santa Fe se convirtió en un enclave importante para las colonias del centro-oeste de la provincia a partir de la creciente infraestructura ferroportuaria. Por otro lado, el período de institucionalización de la obra vial en la 
Szupiany. Del riel al pavimento: la materialización de una disputa en el Litoral argentino.

Argentina, cuando el camino pavimentado comenzó a ser considerado como un signo del progreso técnico y económico. Para una mejor comprensión, y a modo de corolario, los procesos registrados en ambos períodos se esquematizan en la figura 10, detallándose el territorio analizado y la ubicación de las distintas infraestructuras. Las fuentes utilizadas corresponden, por un lado, a crónicas periodísticas y a artículos de opinión y divulgación, publicados —en su mayoría — durante el período de estudio. Por otro lado, se recurrió a estudios especializados en historia de la movilidad y el transporte ferroviario y vial; como así también a estudios académicos vinculados a la historia urbana local. Estas fuentes no sólo han sido indispensables para la reconstrucción de gran parte de los hechos aquí presentados, sino que, al mismo tiempo, han permitido develar ciertos matices de la contienda entre del riel y el pavimento.

\section{Crónica de una contienda}

En 1933 el extenso título de una nota, publicada en la Revista del Puerto de Santa $\mathrm{Fe}$, alertaba acerca de una disputa que devendrá emblemática a lo largo de las décadas siguientes: "La intensificación del transporte por automotores mecánicos crea una situación incómoda a las empresas ferroviarias, la que debe ser contemplada por los poderes públicos". De acuerdo a lo enunciado en el contenido de dicha publicación, se consideraba que la creación de caminos paralelos a las vías ferroviarias trastocó el sentido originario con el que la infraestructura vial había sido pensada y ejecutada a partir de los fondos provenientes de la Ley Mitre, sancionada en $1907^{5}$. Según el espíritu de dicha ley, el camión sólo debía oficiar como una suerte "de intermediario", posibilitando la conexión entre las estaciones de tren y el lugar en el que se originaba la producción agropecuaria destinada a los puertos de ultramar. No obstante, esta "acción coordinada", que redundaba en "beneficios recíprocos", se había visto interrumpida por la decisión de superponer ambos trazados, "perjudicando a mansalva" al ferrocarril, que no contaba con los medios necesarios para ponerse a resguardo de un enemigo tan poderoso y versátil.

Cuando el camión era utilizado como en un principio, para servir de intermediario entre el productor y el ferrocarril, o sea, era utilizado para llevar los productos desde el lugar de producción hasta las estaciones ferroviarias utilizándose los caminos de acceso que iban creándose con los fondos provenientes de la Ley Mitre, el camión constituía una ayuda poderosa para extender el radio de acción de los ferrocarriles existiendo entonces, una acción coordinada que propendía a la intensificación de los transportes dentro de una armonía

\footnotetext{
${ }^{5}$ La Ley 5.315, sancionada en 1907 por iniciativa del Ing. Emilio Mitre, disponía la contribución del 3\% de las ganancias líquidas de los ferrocarriles para la construcción y el mejoramiento de los caminos de acceso a las estaciones ferroviarias, a partir de la creación de un fondo específico para la ejecución de obras viales. Al mismo tiempo, en su artículo $8^{\circ}$, eximía (por el plazo de 40 años, hasta el $1^{\circ}$ de enero de 1947) a las empresas de capitales británicos y franceses del pago de cualquier impuesto, así como también de los derechos aduaneros para importar insumos y repuestos ferroviarios. La caducidad de esta ley fue una de las razones que propició la nacionalización de ferrocarriles durante el gobierno de Juan D. Perón.
} 
que redundaba en beneficios reciprocos. Posteriormente, con la creación de caminos no transversales, sino paralelos a las vías del ferrocarril, dióse origen a una competencia entre el transporte mecánico y el ferrocarril, en la que éste último, por razones obvias, es perjudicado a mansalva, sin que tenga medios de evitar los perjuicios que la nueva situación ha creado ${ }^{6}$.

En efecto, en la medida en que la legislación vial comenzó a cobrar una mayor importancia en la escena y en la planificación urbana, la amenaza que representaba el sistema automotor para la industria y la infraestructura ferroviaria comenzó a hacerse cada vez más evidente. Esta situación derivó, a partir de las décadas siguientes - llegando a su paroxismo en la década de 1990 - en una paulatina descomposición de la red ferroviaria "más extensa de América Latina" (Williams, 2004, p. 76). Siguiendo a Martín Seval et al (2016), puede decirse que la historia del transporte automotor se inicia en la Argentina a principios del siglo XX, pero comienza a tomar impulso como modo de transporte alternativo en la década de 1930, alcanzando su relevancia actual a partir de las políticas desarrollistas iniciadas por el gobierno de Arturo Frondizi. En el período posterior a la crisis de Wall Street, como queda de manifiesto en la nota a la que antes se hizo alusión, la incorporación de la red vial a partir de criterios de competencia comenzó a poner en crisis la articulación que habría pretendido establecerse durante el período anterior, en pleno auge del modelo agroexportador, cuando el transporte vial, el transporte ferroviario y el transporte fluvio-marítimo se organizaban en un círculo virtuoso.

Asimismo, las ciudades del Litoral argentino que habían crecido al ritmo del ciclo agroexportador, convirtiéndose en nodos ferro-portuarios, sintieron las consecuencias de la competencia entre trenes y automóviles en su propia trama urbana. La misma estaba caracterizada por la presencia de grandes infraestructuras ferroviarias y portuarias que, en la medida en que dicho modelo entró en decadencia, fueron convirtiéndose en un obstáculo para la expansión de los barrios y la circulación de los vehículos. En otras palabras, para la construcción de "una urbe del futuro", tal como puede apreciarse en las elocuentes palabras del Ing. Pascual Gagneten, Jefe de Vías y Obras del Ferrocarril General Belgrano, quien caracteriza del siguiente modo el proyecto de restructuración ferroviaria que estaba siendo pensado para Santa Fe hacia mediados de la década de 1960.

Dicho proyecto contempla la eliminación de las vías del radio urbano, mediante la construcción de una estación única de ferrocarriles en la zona oeste, o sea en los terrenos ganados al Salado, por donde pasará la avenida de Circunvalación que construye actualmente Vialidad Nacional. [...] El problema, indudablemente lo merece; y la ciudad próxima a dar un salto insospechado con el túnel [Santa Fe-Paraná] y la autopista [Santa Fe-Rosario], no puede demorar mucho tiempo más.

\footnotetext{
6 Revista del Puerto de Santa Fe, mayo-junio de 1933, p. 3. Asimismo, la nota advertía acerca de la desigualdad de condiciones en la que se realizaba dicha competencia, puesto que los camiones que ingresaban al puerto local se mantenían exentos de las regulaciones y aranceles impuestos a los ferrocarriles.
} 


\begin{abstract}
Deben comenzar de inmediato las tareas de ampliación y limpieza que se imponen para recibir dignamente aquellas obras, propias de una urbe del futuro. Ese futuro que es inaccesible, o es "ya", en la medida que lo aproximan o lo alejan, los ediles de turno ${ }^{7}$.
\end{abstract}

El crecimiento económico y demográfico que experimentó Argentina, entre 1880 y 1930, estuvo inequívocamente ligado al desarrollo de esta infraestructura ferroviaria, respecto de la cual los caminos aún resultaban subsidiarios. Esta expansión fue geométrica, pues pasó de contar con unos pocos kilómetros de vías, hacia mediados del siglo XIX, a una extensión de casi $40.000 \mathrm{~km}$. en poco más de medio siglo. De todos modos, el crecimiento de los caminos de hierro no fue homogéneo a lo largo del extenso territorio nacional, sino que adquirió una impronta muy particular; en los términos de Ezequiel Martínez Estrada (2001[1940]), de espaldas al interior y de cara a Europa. En tal sentido, es indudable que esta particular característica - pampeana o litoral- adquirida por la red ferroviaria se encuentra en estrecha vinculación con la actividad agropecuaria y con su articulación con los puertos ubicados en el frente fluvial conformado por el Río Paraná y el Río de la Plata. Motivo por el cual la red de transporte ferroviario comenzó a adquirir una forma radial y concéntrica, la que se abría en forma de un abanico de diferente envergadura a partir de los principales puertos del país; en particular, los de Buenos Aires, Rosario y Bahía Blanca (Roccatagliata, 2008). Una morfología estructural a la que tampoco pudo escapar el trazado de la red vial troncal, desde el momento en el que comenzó a ser concebida, no ya como un complemento transversal de los ferrocarriles, sino como una posible infraestructura de sustitución. Como se verá más adelante, tal es el caso de la Ruta Nacional N ${ }^{\circ} 11$ en la provincia de Santa Fe.

El transporte automotor, por su parte, comenzó a tomar impulso como un medio alternativo luego de la crisis bursátil del año 1930, situación a partir de la cual se hicieron evidentes los límites del modelo de acumulación agroexportadora y las dificultades que representaba mantener la red ferroviaria asociada al mismo. En ese marco, como señala Ballent (2005), la cultura del automóvil, o "la construcción del universo simbólico del camino", que había venido consolidándose desde la década anterior, experimentó un importante impulso en la Argentina a partir de la sanción de la Ley de Vialidad $\mathrm{N}^{\circ} 11.658$ y de la creación de la Dirección Nacional de Vialidad (DNV), en tanto que estas nuevas vías de comunicación parecían materializar por fin un viejo anhelo compartido por Juan Bautista Alberdi y Domingo Faustino Sarmiento: el de la integración del territorio nacional. Un anhelo que sugería la "epopeya del Estado moderno" - en el que los cuadros técnicos, y sobre todo los ingenieros, adquirirán un rol fundamental - y concitaba el entusiasmo de importantes sectores de la sociedad, excluyendo de ese conjunto, claro, a las empresas ferroviarias. Fue ese primer intento explícito por favorecer la expansión de la infraestructura vial (estimulada, además, por una incipiente industria petrolera, y por una cada vez más explícita disputa entre los

\footnotetext{
7 Revista Tiempo, 15/12/1967, p. 30.
} 
capitales británicos y estadounidenses) ${ }^{8}$, no ya como un complemento sino en directa competencia con el ferrocarril, lo que incidirá en la paulatina y sostenida desarticulación de la red ferroviaria argentina.

Como sugiere Ballent (2005), no obstante, la historia y el desenlace de esta disputa ya se encuentra condensada en Kilómetro 111, una película dirigida y estrenada por Mario Soffici en 1938, cuyo guion había sido escrito por Enrique Amorim. En la trama de esta comedia, Ceferino, el personaje interpretado por Pepe Arias, participa en primera persona de la contienda entre el ferrocarril y el automóvil. El personaje inicia la película como jefe de la estación ferroviaria ubicada en el kilómetro 111, en pleno corazón de la provincia de Buenos Aires. Desde esa posición, y ante el requerimiento de los productores agrícolas, quienes habían obtenido una cosecha particularmente auspiciosa, decide contravenir las ordenes de sus superiores y otorgar a crédito el flete ferroviario de esa producción, que de otro modo tendría que haber sido vendida a un precio mucho más bajo a los acopiadores de granos de la zona. Como consecuencia de dicha indisciplina Ceferino es convocado a la ciudad Capital, para dar explicaciones de lo sucedido, y es finalmente despedido de la empresa ferroviaria. Al regresar a su pueblo, sin embargo, los productores le tienen preparada una sorpresa: en retribución a la ayuda que les había brindado, y utilizando la diferencia obtenida a partir de la venta directa de su producción, los hombres del campo le han comprado una estación de venta de combustibles. De este modo, Ceferino dejaba de ser el jefe de una estación vinculada al pasado y se convertía en el dueño de la que apostaba al futuro. Algo que queda maravillosamente retratado en el discurso con el que cierra el filme, en donde la voz del protagonista - quien inaugura su Estación de Servicio al grito de "el camino es la civilización, el camino es el progreso..." - es sistemáticamente interrumpida por la bocina del tren, que transita por las vías que corren contiguas a un camino cuyo pavimento también se inaugura. El ferrocarril, que en otra época había sido considerado como el máximo estandarte del adelanto civilizatorio ${ }^{9}$, había devenido un obstáculo. Ya era tiempo de mirar hacia adelante, o bien, en palabras más afines al mundo que se avecinaba, de pisar el acelerador.

8 Por un lado, la disputa se producía en el marco de un cambio tecnológico mediante el cual habían comenzado a sustituirse los medios de transporte impulsados por la energía generada a través del calentamiento del agua, por otros medios basados en la energía proveniente de los hidrocarburos, con motor a explosión. Por el otro lado, se daba en un escenario de creciente competencia entre los capitales provenientes de Gran Bretaña, ya en baja por esos años, y Estados Unidos, en franco crecimiento. En efecto, la industria automotriz norteamericana se encontraba en plena expansión, mientras que las tecnologías ferroviarias del siglo anterior, así como también su desarrollo territorial, se encontraban en declive.

9 Al respecto, vale recordar estas palabras de Julio Argentino Roca, pronunciadas en ocasión de su asunción presidencial, en 1880: "El que haya seguido con atención la marcha de este país ha podido notar, como vosotros lo sabéis, la profunda revolución económica, social y política que el camino de hierro y el telégrafo operan a medida que penetran en el interior. Con estos agentes poderosos de la civilización se ha afianzado la unidad nacional, se ha vencido y exterminado el espíritu de la montera y se ha hecho posible la solución de problemas que parecían irresolubles, por lo menos al presente. Provincias ricas y feraces sólo esperan la llegada del ferrocarril para centuplicar sus fuerzas productoras con la facilidad que les ofrezca traer a los mercados y puertos del litoral sus variados y óptimos frutos, que comprenden todos los reinos de la naturaleza". Cit. Romero (2010[1956], pp. 177-178). 


\section{Auges y ocasos en el Litoral santafesino}

Tras el incipiente proceso de conformación de un corredor de crecimiento hacia el este de la ciudad de Santa Fe (luego de su traslado a mediados del siglo XVII), la instalación del Puerto de Colastiné y la consecuente habilitación de un ramal del Ferrocarril Santa Fe (FCSF), ambos en 1886, marcaron el inicio de un lento proceso de urbanización hacia la periferia este santafesina. Sobre todo, a partir de una condición territorial que, como señala Gisela Rausch $(2012$, p. 48), se caracterizaba por la incorporación del territorio al régimen económico mundial. Por su parte, Bertuzzi (2015, p. 24) sostiene: “...ni aquellos asentamientos precarios, ni la posterior fundación de la ciudad de Santa Fe, transforman tan radicalmente el paisaje como lo hacen las fundaciones de colonias agrícola-ganaderas del siglo XIX y el sistema de caminos, puertos y ferrocarriles que las acompañan". En efecto, si bien las colonias instaladas en el "Corredor de la Costa" no adquirieron la misma relevancia y pujanza que alcanzaron las ubicadas en el centro y sur de la provincia, como Esperanza o San Carlos, estas últimas convirtieron a la ciudad de Santa $\mathrm{Fe}$ en el núcleo de una región productora emergente del proceso de colonización agrícola. En este contexto, la dirigencia de Santa Fe propuso la dotación de un puerto en las cercanías de la ciudad central, con el objetivo de colocar dicha producción en las rutas del mercado nacional e internacional.

En ese nuevo escenario comenzó a funcionar el Puerto de Colastiné, en 1886, a cargo de la Compañía Francesa de Ferrocarriles, vinculado directamente con el ramal a Colastiné del Ferrocarril Santa Fe a las Colonias, que unía Santa Fe y Esperanza desde 1885. Construido por la Compañía inglesa J.C. Meiggs, este ramal se extendió hasta el poblado de San José del Rincón en 1888, ofreciendo un servicio regular de trenes de pasajeros. A partir de estas transformaciones, entre 1890 y 1910 la actividad del puerto adquirió un gran dinamismo y un alto protagonismo en la región, convirtiéndose en el segundo puerto de mayor jerarquía de la provincia de Santa Fe. No obstante, su desafortunada implantación sobre el valle de inundación del Río Paraná impulsó a la dirigencia santafesina a construir un nuevo puerto. De este modo, el Puerto de Ultramar quedó inaugurado en 1911, mientras el Puerto de Colastiné fue desmantelado en 1912 y cerrado definitivamente en 1926. A partir de este momento, la pérdida de gravitación de dicha zona marcará un punto de inflexión en el desarrollo de la periferia este de Santa Fe (Figura 2).

En este corto período de auge y ocaso, vinculado de modo directo al desarrollo ferroportuario de la región, fue significativa la incorporación de nuevas infraestructuras de conexión sobre el curso de la Laguna Setúbal. En efecto, el paisaje costero de la ciudad se vio alterado por la construcción de tres puentes ferroviarios, financiados por la Compañía Francesa de Ferrocarriles. El primero de ellos comenzó a funcionar en 1886, sobre la traza del ramal al puerto de Colastiné, ubicada en la desembocadura de la Laguna Setúbal. Su funcionamiento se extendió casi por dos décadas, hasta 1905, momento en que colapsó debido a una gran crecida del Río Paraná. Durante dos años el movimiento ferroviario entre Santa Fe y Colastiné se mantuvo suspendido, hasta la habilitación de un segundo puente en 1907. El nuevo ramal se construyó 1,5 kilómetros al norte del anterior, manteniéndose activo, aunque con un reducido funcionamiento tras el desmantelamiento del Puerto de 
Colastiné, hasta 1926, momento en el que su estructura colapsó ante una nueva crecida del Paraná. El tercer y último puente ferroviario sobre la Laguna Setúbal comenzó a idearse en 1927, a pedido de la Dirección General de los Ferrocarriles del Ministerio de Obras Públicas de la Nación, quedando habilitado en el año 1935. A diferencia de sus antecesores, que habían sido construidos en madera, éste se materializó en hierro y hormigón, imponiendo una imagen técnica y estética renovada a partir del despliegue de sus cuatro arcos metálicos. Sin embargo, aún hoy se desconocen los motivos que impulsaron su reconstrucción tras el cierre definitivo del Puerto de Colastiné, en 1926. De hecho, ante su evidente ineficacia, en 1943, el puente fue desmontado y trasladado a la provincia de Mendoza, donde fue reutilizado en el Ferrocarril Trasandino (Figura 3).

Figura 2. Puertos de Santa Fe; (1) ramal FCSF a Colastiné;

(2) Puerto de Colastiné; (3) Puerto de Ultramar

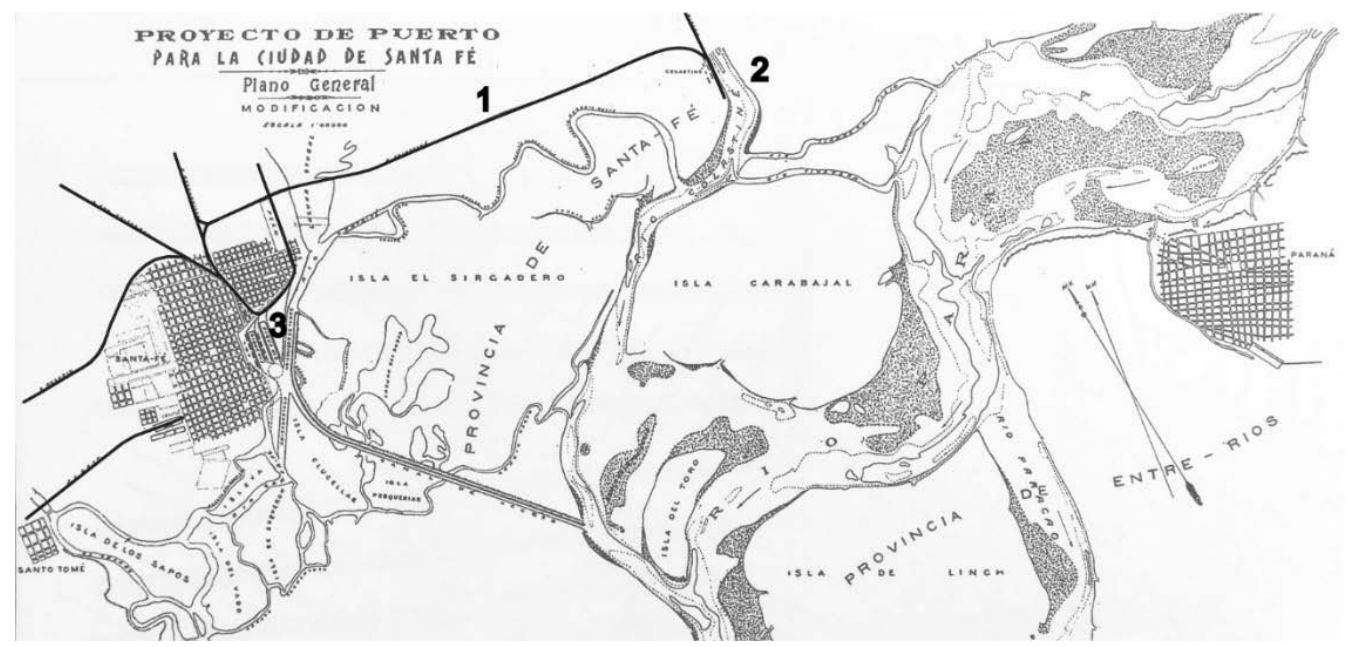

Fuente: Intervención propia sobre plano general del nuevo Puerto de Ultramar, 1911. Archivo General de la Provincia de Santa Fe.

Ahora bien, al tiempo que se modificaba el paisaje costero a partir de la incorporación de estas infraestructuras, el Camino de la Costa oficiaba como un medio complementario al ferrocarril para la comunicación de los asentamientos del corredor, precisamente en el tramo comprendido entre el pueblo de Rincón y Colonia Helvecia, localidades que carecían de redes ferroviarias. No obstante, la precariedad de su trazado y el anegamiento de su calzada en épocas de crecida, lo tornaban intransitable durante largos períodos. Esta condición quedó esbozada en la prensa local de las primeras décadas del siglo XX, junto a reiterados reclamos para su mejoramiento. Las notas periodísticas dejan entrever el incipiente avance de la obra vial en al ámbito local. Entre las más relevantes se destacan las siguientes: en primer lugar, una petición presentada por vecinos del departamento Garay a la Comisión Nacional de Puentes y Caminos para la construcción de un camino desde Helvecia hasta el empalme con el ramal a Rincón del FCSF. En la misma nota, se resalta esta conexión en el marco de la red 
de comunicaciones y transportes que impulsa el dragado del riacho, obra central de la construcción del nuevo Puerto de Ultramar ${ }^{10}$. En segundo lugar, una declaración del gobernador, donde se compromete a encomendar los estudios preliminares para la construcción del camino en cuanto desciendan las aguas. En dicha nota el redactor expresa: "Hora era de que al Este de la segunda provincia argentina, se le diesen medios de comunicación de que ya no carece ni la Siberia" ${ }^{11}$. En tercer lugar, la sanción del senado de la provincia al proyecto que destina 20.000 pesos para arreglos del camino ${ }^{12}$. En cuarto, la solicitud de gestiones para la reparación del puente sobre el Arroyo Leyes ${ }^{13}$. En quinto, el aislamiento agravado de las colonias de la costa y su condición relegada respecto de las colonias del interior ${ }^{14}$. Finalmente, la reparación del camino entre las ciudades de Santa Fe y San José del Rincón por parte de la intendencia municipa ${ }^{15}$.

Figura 3. Puentes ferroviarios sobre Laguna Setúbal; (arriba) primer puente de madera, 18861905; (abajo) puente de hierro y hormigón, 1927-1943
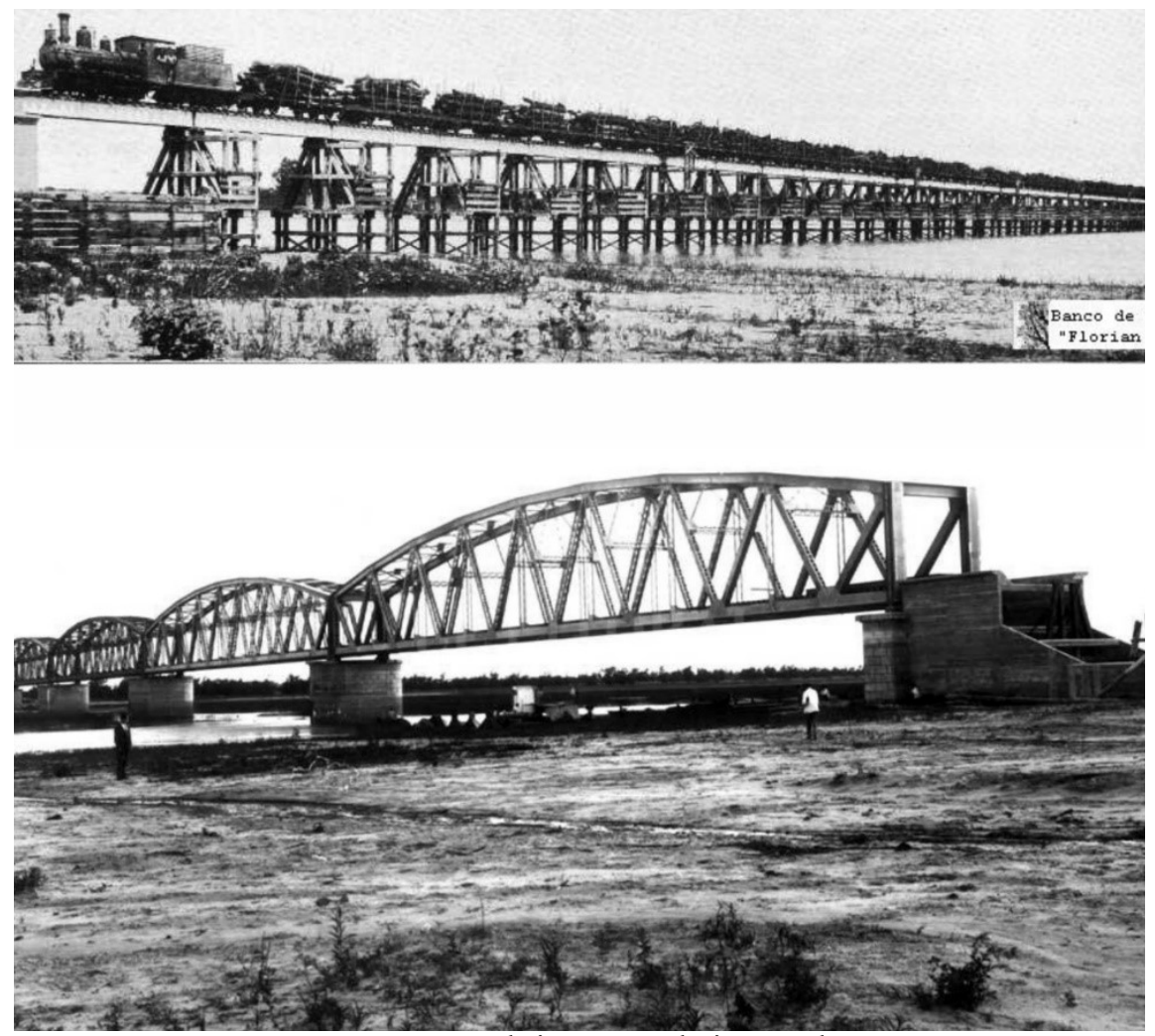

Fuente: Banco de imágenes Florián Paucke

${ }^{10}$ Diario Santa Fe, 5/07/1911.

${ }^{11}$ Diario Santa Fe, 22/06/1912.

${ }_{12}$ Diario Santa Fe, 24/06/1913.

${ }_{13}^{13}$ Diario Santa Fe, 8/03/1922.

${ }^{14}$ Diario Santa Fe, 4/10/1923.

${ }^{15}$ Diario El Orden, 9/02/1929. 
En sintonía con lo experimentado hacia el este de la ciudad de Santa Fe, sobre la Laguna Setúbal, el desarrollo ferroportuario materializó una serie de transformaciones territoriales y urbanas que también influyeron de modo decisivo en la expansión hacia el sudoeste de la ciudad, vinculada con el curso del río Salado. Iniciados los trabajos del Ferrocarril Santa Fe a las Colonias, en 1884, Roverano (1961) detalla la inquietud que experimentaban los comerciantes y vecinos oriundos de los pueblos y colonias del centro-oeste de la provincia acerca de la incorporación de sus incipientes núcleos urbanos en el proyecto de extensión de líneas férreas. En un petitorio al gobierno provincial, los habitantes de la zona expresaron la necesidad de construir un ramal desde Santo Tomé hasta San Carlos, previendo el empalme de esta colonia con un ramal proveniente de Esperanza. Por otro lado, en este mismo petitorio se refleja el interés por revalorizar el Puerto de Santo Tomé ${ }^{16}$, en tanto posible punto de salida de la producción de dichas colonias. A pesar de las peticiones y tratativas, el proyecto del ramal Santo Tomé-San Carlos jamás llegó a concretarse, hecho que, sumado al auge del Puerto de Colastiné, derivó en la decadencia de aquel viejo puerto sobre el Río Salado.

La conexión ferroviaria de Santa Fe con los centros productivos del sur Rosario y Buenos Aires - no obstante, precisó, nuevamente, atravesar el Salado a través de "El Paso". En ese marco, se construyó el edificio de la estación del FCCA (antes llamado Ferrocarril Buenos Aires y Rosario) en el año 1889 y, posteriormente, el ramal del FCSF, impulsando en sus alrededores nuevos focos de crecimiento en el poblado de Santo Tomé. Durante este período, al igual que la Laguna Setúbal, el Río Salado fue escenario del emplazamiento de nuevas infraestructuras de conexión. Sobre las trazas de ambos ramales se erigieron dos conexiones ferroviarias, ubicadas entre los actuales puentes de la Autopista Santa Fe-Rosario, al norte, y carretero, al sur. Al presente, el puente del FCSF, hoy Ferrocarril Nacional General Bartolomé Mitre, mantiene su uso original, tras ser redimensionado en el año 1980.

Hasta aquí, se ha puesto de manifiesto la notable importancia que asumió el sistema ferroportuario en la vinculación de Santa Fe con su territorio circundante (a través de las localidades de Santo Tomé y San José del Rincón), a lo largo de las últimas décadas del siglo XIX. Sin embargo, algunos años más tarde, al momento de la caída del segundo puente ferroviario extendido sobre la Laguna Setúbal, en 1926, se divisaba ya en el paisaje costero la figura de un nuevo puente-acueducto vial. El emblemático Puente Colgante, que luego se convertiría en un símbolo del patrimonio cultural santafesino, fue construido con el objetivo de resolver el abastecimiento de agua de la ciudad, conectando la toma ubicada en San José del Rincón con la planta potabilizadora emplazada en el Barrio Candioti. Tras una serie de intentos por salvar dicha distancia, y de distintas alternativas elaboradas y ejecutadas por la Dirección Nacional de Obras de Salubridad entre 1903 y 1921 (Collado y Muller, 2012), se iniciaron los estudios para la ejecución de un puente carretero.

${ }^{16}$ El Puerto de Santo Tomé fue creado en 1846 como estación de resguardo aduanero sobre el río Salado, cobrando un fuerte impulso a partir de la fundación de las colonias agrícolas del oeste. Sin embargo, su dinamismo decreció hacia finales del siglo XIX, cuando el tendido de las nuevas redes ferroviarias eludió el Paso para concentrarse en el Puerto de Santa Fe. 
Con ese fin se determinó la construcción de un puente de acero con dos pilares de apoyo, a partir de los cuales se erigieron las torres, desde donde se mantenía suspendida la calzada destinada al tránsito vehicular. Luego de cuatro años de iniciada su construcción el Puente Colgante fue habilitado para todo tipo de tránsito, en 1928. Ahora bien, más allá de la función principal que le dio origen, es decir, la provisión de agua a la ciudad de Santa Fe, y del valor histórico patrimonial que más tarde alcanzó, el nuevo puente se materializó como un hito de enorme significación en el marco de la incorporación del automóvil a la vida urbana del ámbito local. Tras el colapso del puente ferroviario y la consecuente situación de aislamiento que experimentaban los asentamientos y localidades de La Costa, el Puente Colgante dio comienzo a un nuevo período de la movilidad territorial hacia el este de la ciudad y, en definitiva, representó un mojón insoslayable en la genealogía de la prolífica obra vial posterior. En una palabra, fue el símbolo más emblemático del inicio de una nueva era en la historia de la movilidad en la ciudad de Santa Fe. El riel empezaba a dejar paso al pavimento (Figuras 5 y 6 ).

Figura 4. Puente del FCSF sobre Río Salado, actualmente en uso
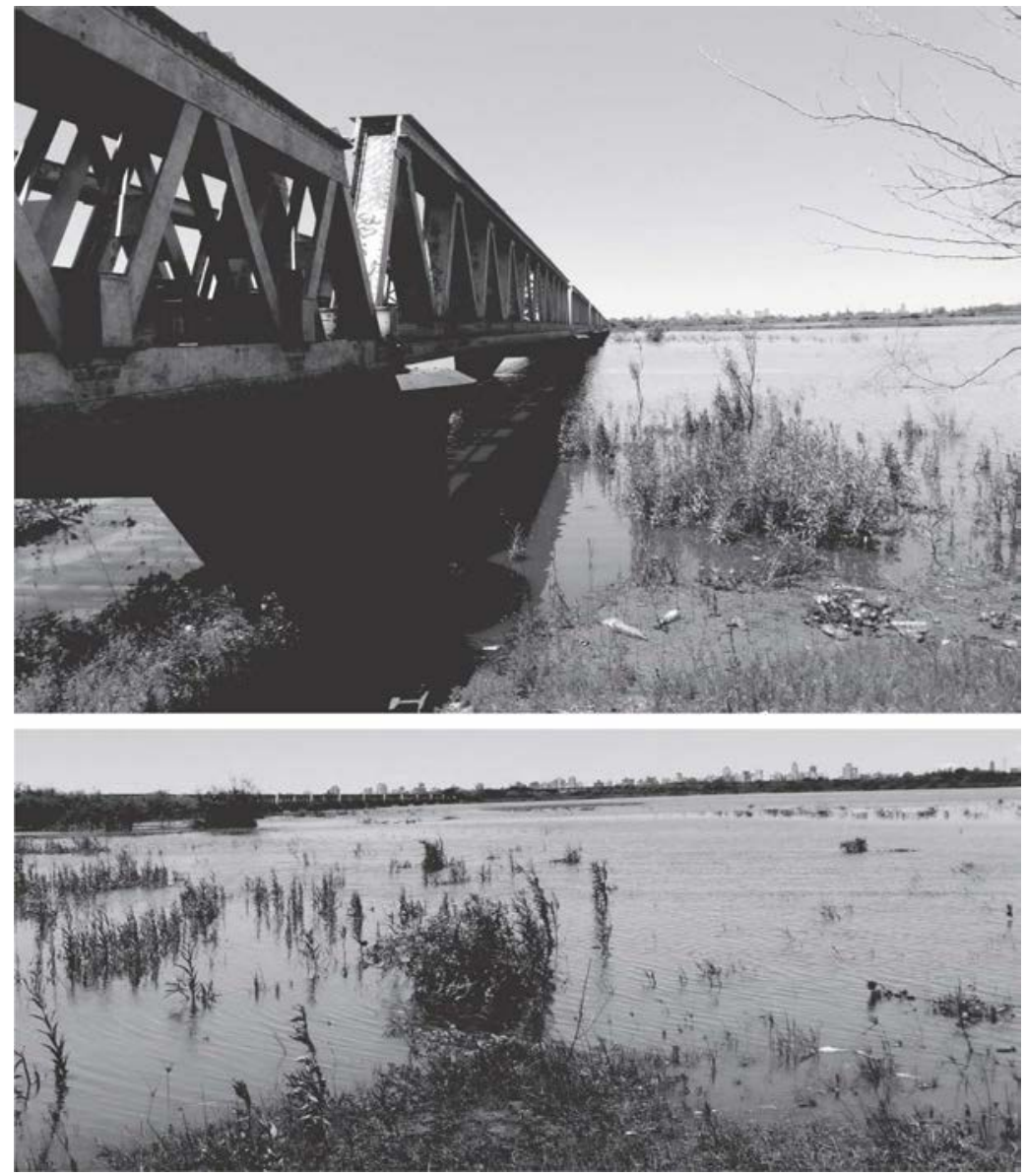

Fuente: fotografía de la autora 
Figura 5. Vista del Puente Colgante durante la construcción del acceso oeste, 1925

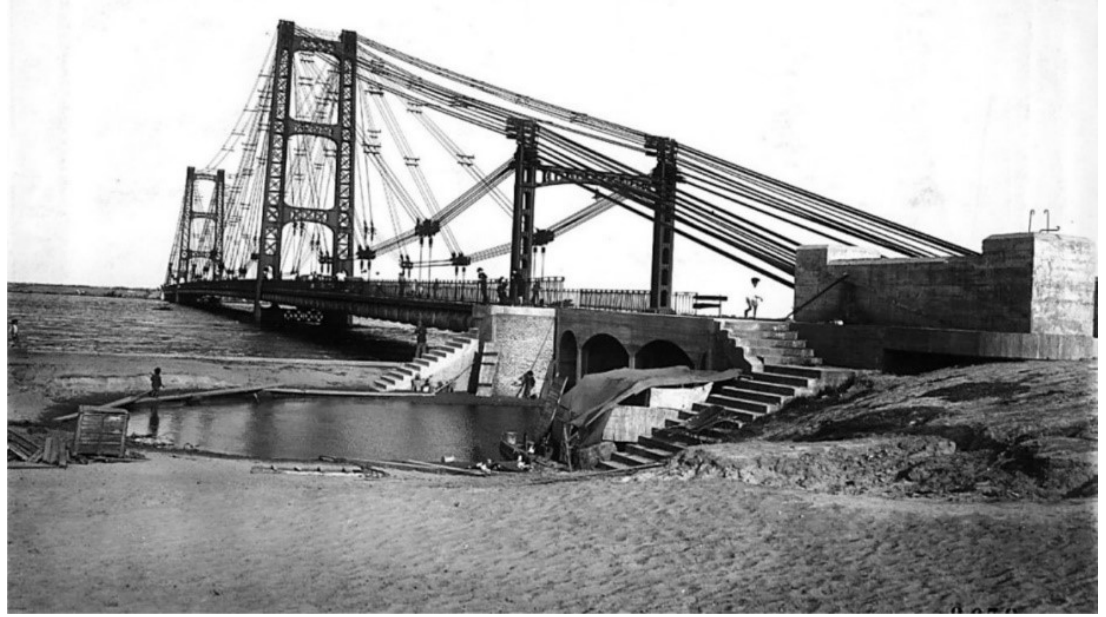

Fuente: Archivo Diario El Litoral

En efecto, al mismo tiempo que culminaban las obras sobre este nuevo puente, se completó el Camino de la Costa desde el extremo este del Colgante hasta el poblado de San José del Rincón. Se concretó, de este modo, la continuidad vial entre aquella villa litoral y la ciudad de Santa Fe. Inicialmente designado como camino de jurisdicción nacional, el Camino de la Costa integró la Ruta Nacional $N^{0} 168$, que se extendía entre Santa Fe y Helvecia. Más tarde, su jurisdicción quedó a cargo de la Dirección Provincial de Vialidad, pasando a conformar la Ruta Provincial No⒈ Por otra parte, aquel camino nacional incluía el tramo desde el paraje La Guardia hasta el servicio de balsas, dispuesto sobre el Río Colastiné, para el cruce a la ciudad de Paraná, bifurcación que todavía mantiene su designación como RN168. No obstante, durante los "gloriosos" años de la vialidad nacional, más precisamente, entre 1932 y 1946, los caminos de la periferia este santafesina quedaron excluidos de los planes destinados al sistema troncal de caminos nacionales. Las primeras intervenciones, conseguidas luego de insistentes reclamos y la elevación de diversos petitorios por parte de la comunidad local, consistieron en la pavimentación del Camino de la Costa -RP1- entre 1944 y 1954, en la construcción y pavimentación del camino de acceso al Río Colastiné -RN168-, en 1941, y en la prolongación de este último hasta el Río Paraná, en 1952.

Por su parte, la movilidad del territorio santafesino hacia el sudoeste (a través de "El Paso") comenzó a concretarse por medio de la construcción del primer puente de madera sobre el Río Salado en 1875 (reparado en 1879 y 1904) definiendo la traza de las sucesivas conexiones entre las ciudades de Santa Fe y Santo Tomé. No obstante, en 1906 fue reemplazado por un puente de hierro levadizo de siete tramos unidos por un terraplén. Esta nueva conexión vial permitía el paso de las embarcaciones, que tenían sus atracaderos en las barrancas del Puerto de Santo Tomé, y por el cual 
transitaban alrededor de cien vehículos diarios a comienzos de la segunda década del siglo $\mathrm{XX}^{17}$. Sin embargo, la precariedad de su estructura se manifestaba cada vez que el Río Salado experimentaba una nueva crecida, por lo que las comunicaciones entre ambos núcleos urbanos se mantuvieron con serias dificultades a lo largo de casi 30 años, entre desmoronamientos, clausuras, arreglos, refuerzos y habilitaciones (Figura 7). A lo largo de este período, la prensa local asumió un rol muy importante en los continuos reclamos para su reemplazo y/o reparación, al tiempo que auspiciaba en sus notas el desarrollo de "aquel pintoresco pueblo", el cual se encontraba directamente ligado a una vía de comunicación que fuera capaz de garantizar las relaciones de manera sostenida: "El progreso efectivo de aquel pintoresco pueblo depende solamente de una vía de comunicación que garantice el desenvolvimiento regular de las relaciones comerciales. Su proximidad a la capital y lo agradable de su paraje, autorizan a pensar que Santo Tomé será en plazo no lejano un pequeño emporio de actividades y una residencia ideal" ${ }^{18}$. El funcionamiento del puente de hierro se extendió hasta la habilitación de la nueva conexión vial, en 1939, siendo desmantelado de manera definitiva en $1950^{19}$.

Figura 6. Vista aérea de la Laguna Setúbal durante el breve período en el que convivieron ambos sistemas de transporte. Arriba, Puente Colgante (inaugurado en 1928); abajo, tercer puente ferroviario (1927-1943)

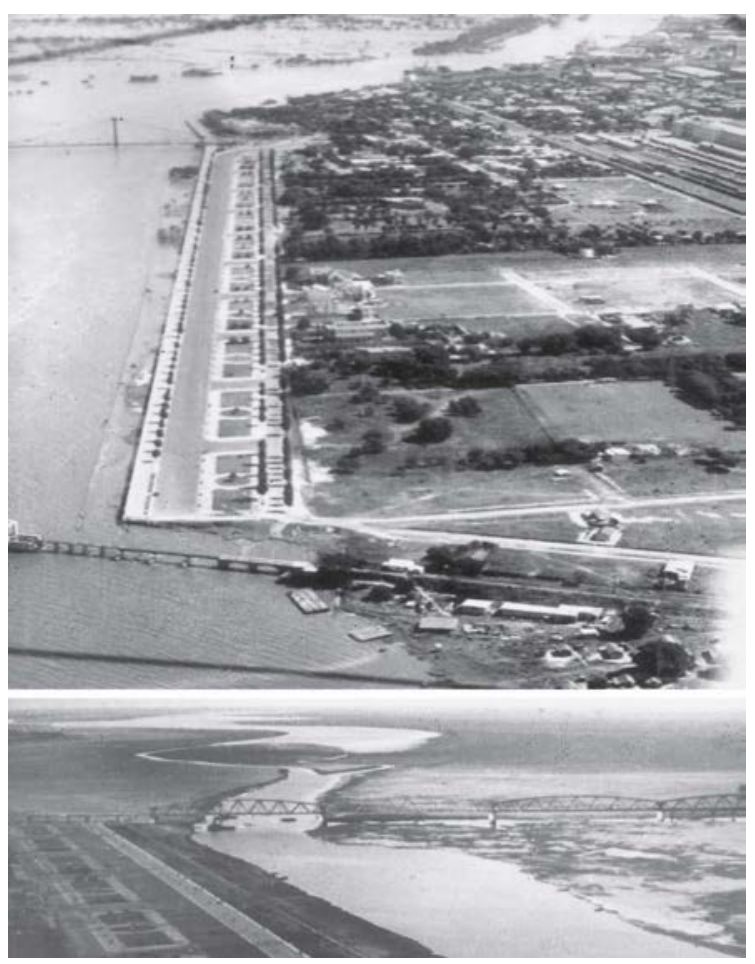

Fuente: Archivo Diario El Litoral

\footnotetext{
${ }^{17}$ Diario Santa Fe, 9/06/1912.

${ }_{18}$ Diario Santa Fe, 23/07/1915.

${ }^{19}$ Diario El Orden, 7/06/1950.
} 
Figura 7. Puentes carreteros sobre Río Salado; (arriba) puente de madera, 1875-1906; (abajo) puente de hierro levadizo, 1906-1939
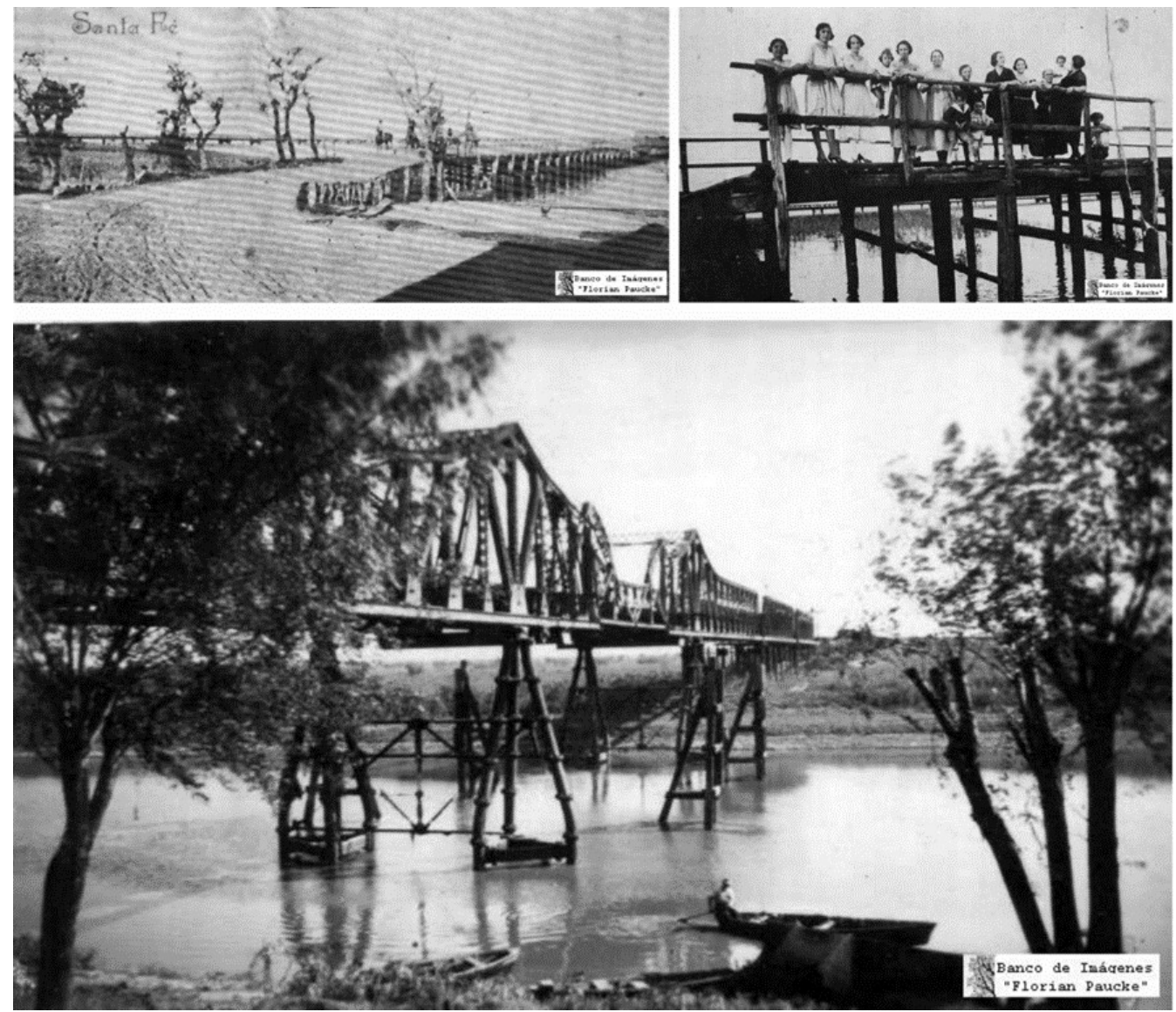

Fuente: Banco de imágenes Florián Paucke

La solución definitiva se concretaría algunos años más tarde, en el marco del trazado de las primeras rutas proyectadas y pavimentadas de la provincia de Santa $\mathrm{Fe}$, en este caso, la Ruta Nacional $N^{\circ} 11$. Su origen se remonta al año 1927, cuando el Poder Ejecutivo sanciona la Ley Provincial No 2.157 destinada a la construcción de "calzadas endurecidas". Entre los tramos previstos, la ley incluía los caminos extendidos entre las ciudades de Rosario y Santa Fe, así como también entre las ciudades de Santa Fe y San Justo, con una longitud aproximada de $170 \mathrm{~km}$. y $100 \mathrm{~km}$. respectivamente. Tras la creación de las Comisiones de Estudio, en 1928, y la Sección de Inspección de las obras de la mencionada ley, en 1930 se inició la pavimentación de ambos tramos, en una tarea que estuvo a cargo de la Dirección de Obras Públicas, Tierra y Geodesia de la provincia de Santa $\mathrm{Fe}^{20}$. En el marco de estos trazados, se construyó un nuevo puente carretero sobre el Río Salado entre las ciudades de Santa Fe y Santo Tomé, cuyos

${ }^{20}$ Revista del Puerto de Santa Fe, agosto de 1929. 
vaivenes y particularidades se esbozan más abajo. En 1932, luego de la sanción de la Ley de Vialidad $\mathrm{N}^{\circ} 11.658$ y la subdivisión del territorio nacional en VIII regiones para la numeración de rutas nacionales, los caminos pavimentados Rosario-Santa Fe y Santa Fe-San Justo comenzaron a formar parte del trazado de la RN11. Esta ruta constituía uno de los grandes itinerarios nacionales en sentido norte-sur, cuyo trazado oficial comienza en Rosario y se extiende hasta la localidad formoseña de Clorinda y su puerto adyacente sobre el río Pilcomayo, frente a la capital de la República del Paraguay (Figura 8).

Figura 8. Trazado de la Ruta Nacional $N^{0} 11$

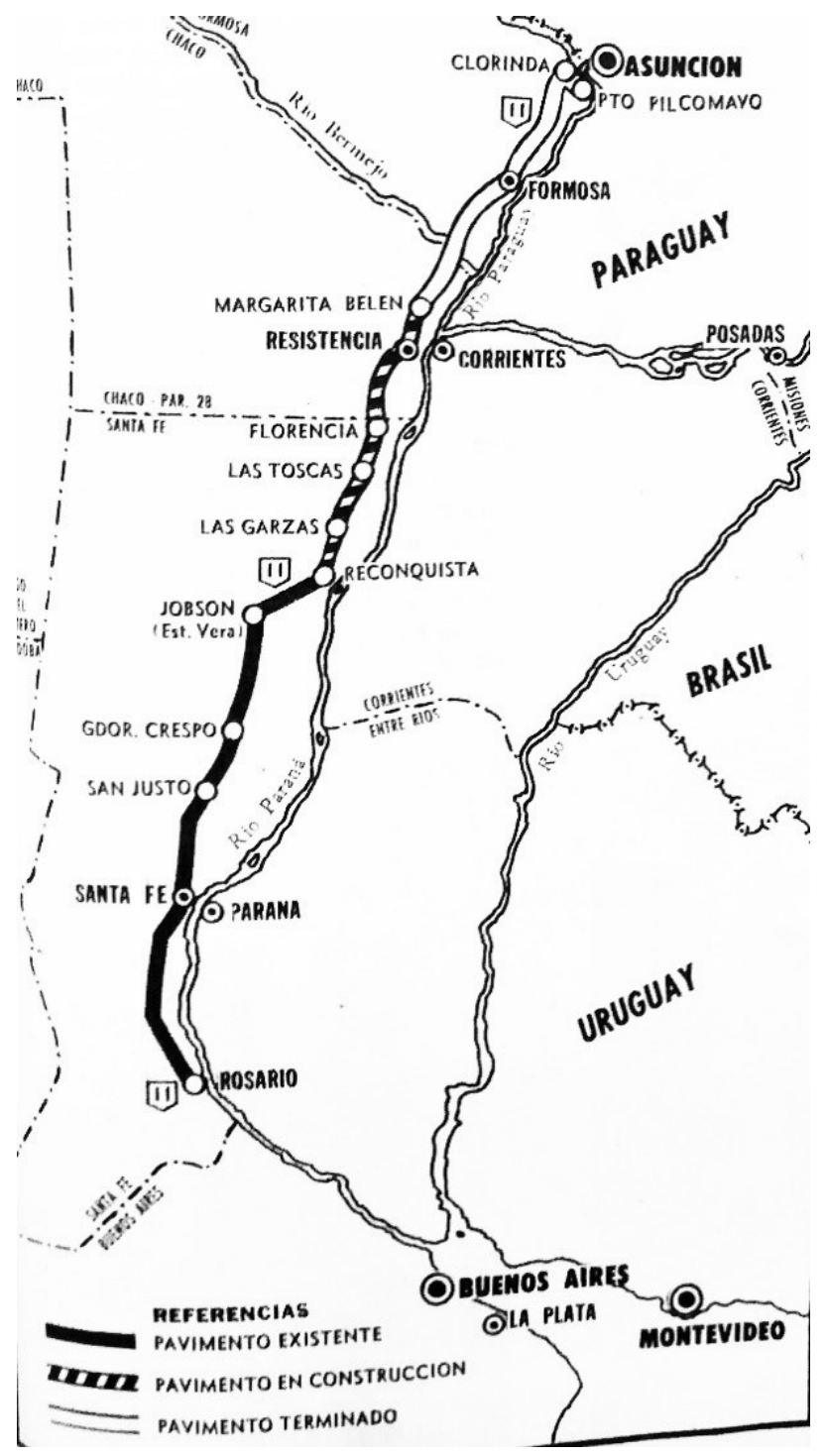

Fuente: Revista Parabrisas, 1964, n 45, p. 51. 
Ahora bien, retomando la crónica acerca de las conexiones sobre el Río Salado, hacia mediados de la década de 1930 la DNV anunció, por primera vez, la construcción de un nuevo puente sobre el trazado de la carretera Rosario-Santa Fe. En efecto, la creciente experimentada por el río en el año 1935 marcaría un punto de inflexión en las gestiones tendientes a buscar una solución definitiva, respecto de la infructuosa comunicación entre las ciudades de Santa Fe y Santo Tomé. Con ese fin, luego del desmoronamiento de los estribos ubicados en el quinto tramo del viejo puente metálico, se conformó la Comisión Pro-Trazado del Nuevo Puente sobre el Río Salado ${ }^{21}$. A partir de estas peticiones, la DNV se inclinó a favor de la ejecución de una obra definitiva que superase los retoques parciales a los terraplenes o la simple construcción de calzadas sobre los mismos ${ }^{22}$. En función de este anuncio, no tardaron en hacerse visible las expectativas generadas a nivel regional, más allá de las ciudades cabeceras. En una asamblea vecinal, convocada por la comuna de Santo Tomé y por la Comisión ProTrazado para tratar la ubicación de la nueva traza, participaron representantes de las comisiones de fomento y municipalidades del sur y del oeste de la provincia de Santa Fe, entre las que se destacaban las localidades de San Lorenzo, Piamonte, Saa Pereyra, San Carlos Centro, Monje, Sastre, San Agustín, Rigby, Gálvez, Loma Alta, Gessler, Carcaraña, entre otras ${ }^{23}$.

Pasados algunos años de aquel anuncio, en 1936 arribó a Santa Fe una comisión de técnicos de la DNV a fin de estudiar la ubicación de los estribos del nuevo puente ${ }^{24}$. Hacia fines de ese mismo año, luego de atravesar el proceso correspondiente de licitación pública, la obra fue adjudicada a la empresa Gruen y Bilfinger S.A. de Buenos Aires ${ }^{25}$ $\mathrm{y}$, algunos meses más tarde, fueron presentados los planos definitivos del puente junto a los detalles técnicos de las obras complementarias de urbanización, que habrían de realizarse en los terrenos ganados a los bañados del Salado ${ }^{26}$. Cumplido el plazo estimado, el nuevo puente carretero quedó habilitado en julio de 1939 (Figura 9). A tan sólo dos años de su habilitación, el nuevo puente representaba uno de los puntos más transitados de la provincia de Santa Fe junto al puente Molino Blanco, el cual se encontraba emplazado en la salida de Rosario hacia Buenos Aires ${ }^{27}$. En efecto, la utilidad del puente creció exponencialmente a lo largo de las décadas siguientes, al tiempo que comenzó a advertirse su inminente obsolescencia ante el incesante aumento de la movilidad de cargas interprovinciales e internacionales. En la década de 1970, la crónica periodística refleja los continuos inconvenientes que se producen en su trayecto ${ }^{28}$.

\footnotetext{
${ }^{21}$ Revista Santo Tomé, 26/08/1937.

${ }^{22}$ Diario El Litoral, 7/12/1934.

${ }^{23}$ Diario El Orden, 6/05/1935.

${ }^{24}$ Diario El Orden, 16/02/1936.

${ }^{25}$ Diario El Orden, 13/12/1936.

${ }^{26}$ Diario El Orden, 10/03/1937.

${ }^{27}$ Diario El Litoral, 31/01/1942.

${ }^{28}$ Diario El Litoral, 20/02/1976.
} 
Szupiany. Del riel al pavimento: la materialización de una disputa en el Litoral argentino.

Figura 9. Puentes carreteros sobre Río Salado; (arriba-izq.) puente de hierro levadizo, 1906-1939; (arriba-der.) nuevo puente de hormigón, 1939. Fuente: Boletín de la Dirección de Obras Públicas de la Provincia de Santa Fe, 1941, pp. 44-45; (abajo) uno de los arcos del nuevo puente

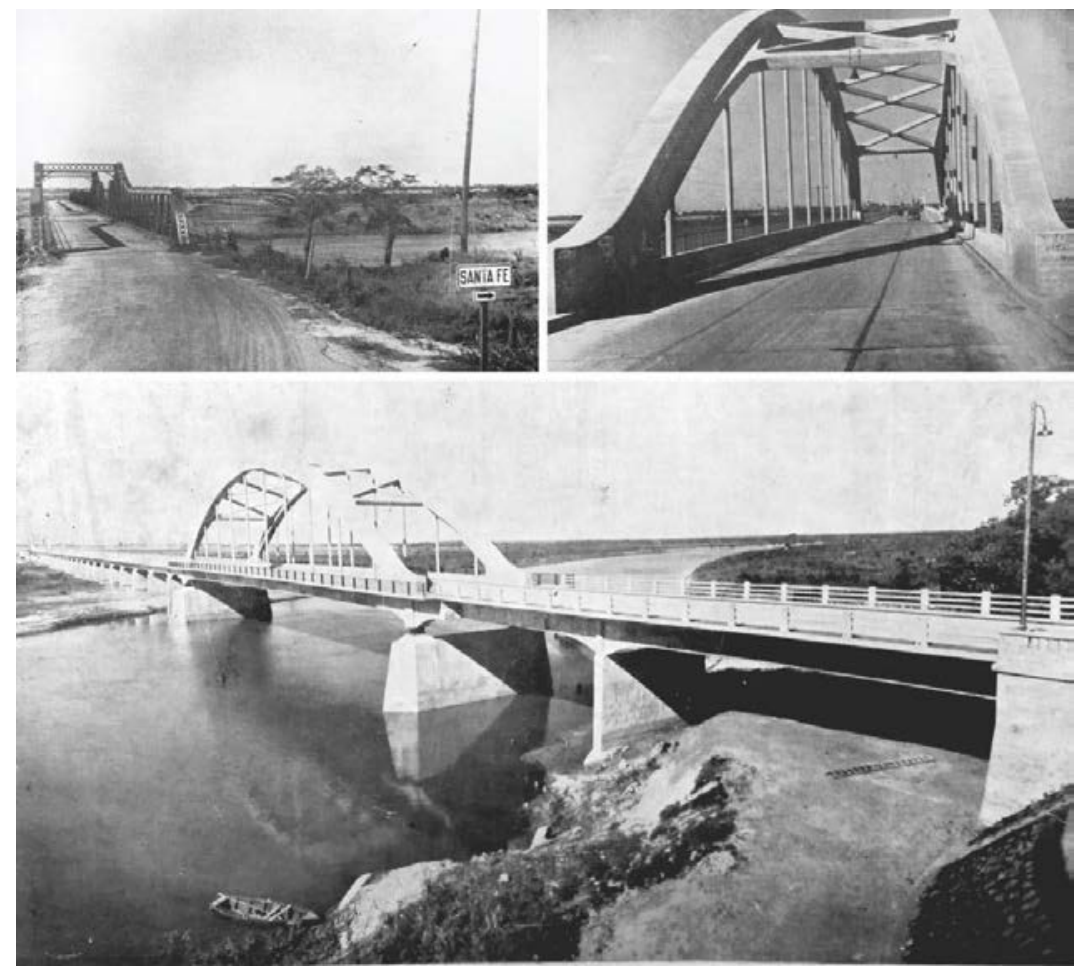

Fuente: Revista Técnica y Arte, 1940. Santa Fe: Asociación Técnicos Nacionales.

$*$

A modo de corolario, y de acuerdo a lo hasta aquí relatado, en la figura 10 queda reflejado, de manera gráfica, el proceso de sustitución de infraestructuras de conexión en el entorno fluvial comprendido entre las ciudades de Santa Fe, San Tomé y San José de Rincón. Sobre la base del crecimiento urbano verificado en los años 1824, 1907 y 1935 , la figura presenta tres esquemas: en el superior, se esbozan los primeros cruces sobre rieles, destacándose el entramado de la red ferroportuaria y los caminos preexistentes. Entre estos últimos, los antiguos caminos a las ciudades de Córdoba y Buenos Aires a través de "El Paso" de Santo Tomé y el Camino de la Costa hacia el poblado de San José del Rincón. En el segundo esquema (medio), pueden observarse los nuevos cruces sobre ruedas, construidos en el marco del trazado de las primeras rutas nacionales y provinciales - por caso, la RN11, la RN168 y la RP1 - manteniendo las direccionalidades de los antiguos caminos. Finalmente, en el tercer esquema (abajo), se detalle con mayor precisión la localización de los cinco puentes ferroviarios y los cuatro viales.

Si se observa el avance de la mancha urbana hasta el año 1935, y se la compara con el crecimiento urbano alcanzado en la actualidad (ver figura 1, mancha urbana de 
2018), puede entreverse cómo el patrón tradicional que estructuró el antiguo modelo de crecimiento, en torno a las estaciones ferroviarias, mutó hacia un modelo expansivo en el que las rutas y autopistas se convirtieron en el factor determinante de la producción y rentabilidad del suelo urbano. Esto se evidencia, fundamentalmente, en la mancha urbana de Santo Tomé, la que comenzó a expandirse hacia el sur en torno al trazado de la RN11, alejándose, paulatinamente, de las estaciones ferroviarias. Por su parte, el Puente Colgante sobre la Laguna Setúbal, en construcción al momento de la caída del segundo puente ferroviario en 1926, impulsó un nuevo período en la movilidad territorial hacia los asentamientos y localidades de la costa, marcando un punto de inflexión en el proceso de urbanización sobre la RN168 y la RP1.

Figura 10. Proceso de sustitución de infraestructuras de conexión en el entorno fluvial de las ciudades de Santa Fe, San Tomé y San José de Rincón

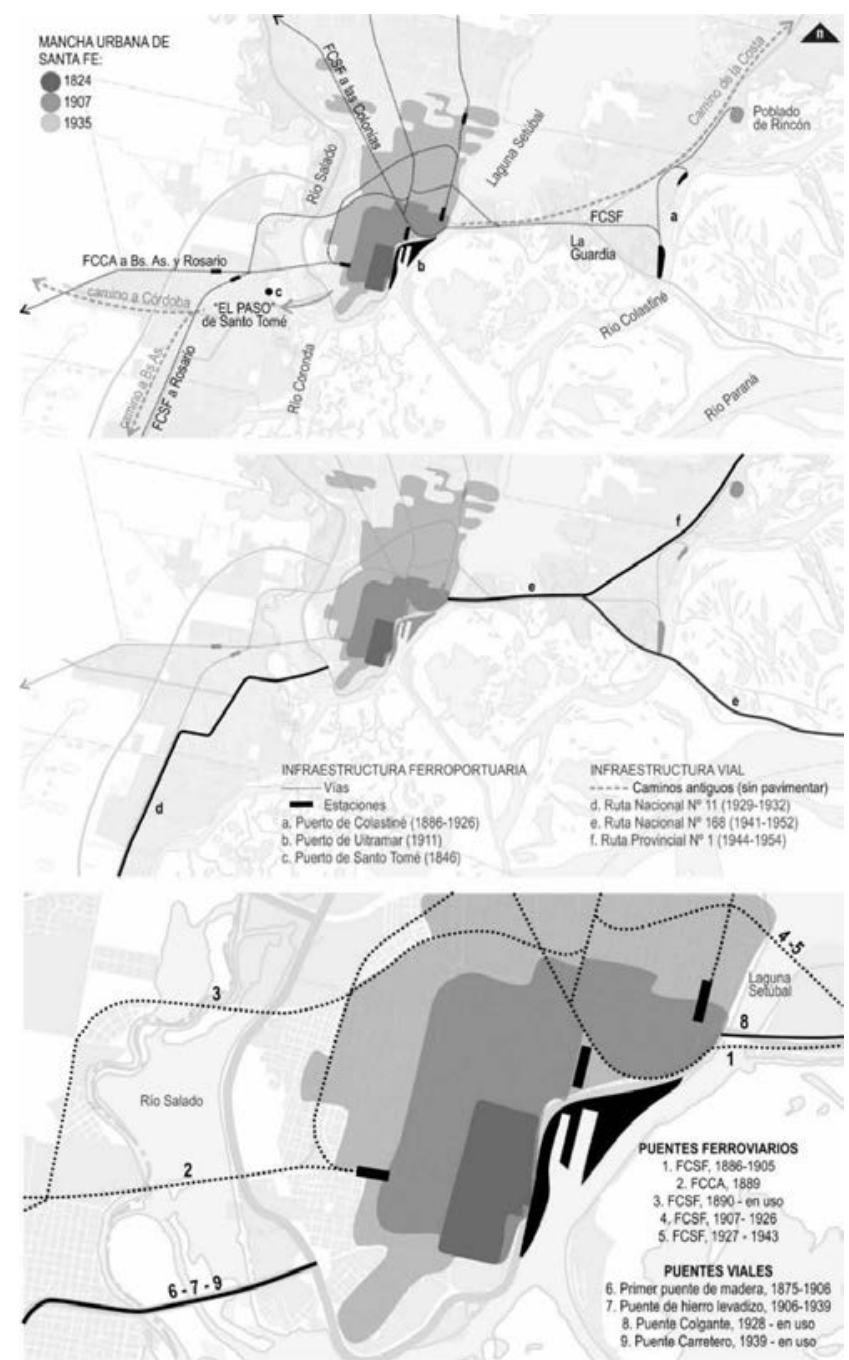

Fuente: Elaboración propia 


\section{Consideraciones finales}

El proceso de sustitución de infraestructuras de conexión en el entorno fluvial comprendido entre las ciudades de Santa Fe, Santo Tomé y San José del Rincón, da cuenta de las transformaciones (urbanas, regionales y territoriales) que desencadenó la disputa entre la infraestructura ferroviaria y la infraestructura vial. Una disputa a partir de la que, al fin de cuentas, el riel terminó por dejar paso al pavimento. Dos tecnologías de transporte cuya interacción no llegó a concretarse en un círculo virtuoso de complementación, tal como había sido ideada a principios del siglo XX, sino que derivó en la paulatina descomposición de la red ferroviaria nacional y, al mismo tiempo, en la proliferación de la obra vial.

A través de la crónica de los sucesos acontecidos en una ciudad del Litoral argentino, se buscó dar cuenta del modo en que dicha disputa se materializó en la escena urbana local. En primer lugar, cuando la infraestructura ferroportuaria -en el marco del modelo agroexportador-, convirtió a la ciudad de Santa Fe en un enclave importante para las colonias del centro-oeste de la provincia, momento en el que los caminos terrestres aún resultaban subsidiarios. En una etapa posterior, cuando el camino pavimentado comenzó a ser considerado como un signo del progreso técnico y económico durante el período de institucionalización de la obra vial en la Argentina, período en el que se llevó a cabo un proceso de modernización con la creación de la DNV y la construcción de las primeras rutas nacionales y provinciales.

De allí que el trazado de la RN11, extendido paralelamente a las vías del ferrocarril a Buenos Aires y Rosario, no sólo representa un hito importante en el proceso de sustitución de infraestructuras de conexión, con el Puente Carretero sobre el Río Salado como símbolo de dicha transición en la escena local. Sino que, al mismo tiempo, representa una de las trazas centrales de la red vial troncal del país, que reprodujo la morfología estructural (radio céntrica) del sistema ferroportuario. En efecto, mientras la RN11, extendida en sentido norte-sur, se convertía en una obra vial prioritaria para la provincia de Santa Fe, la pavimentación del Camino de la Costa, extendido en sentido este-oeste, y su conversión en RP1 y RN168, quedó postergada en función de su posición en la red troncal de caminos nacionales. Hecho que reafirmó la centralidad de Buenos Aires, en la organización del territorio nacional, y de Rosario en el territorio provincial. De este modo, la superposición de las redes y su escasa complementariedad facilitó la competencia entre ambos modos de transporte.

Una vez finalizado aquel primer período de desarrollo vial, el cual se vio interrumpido en 1943, el ciclo económico desarrollista que se pondrá en marcha entre fines de la década de 1950 y principios de 1960 impulsó un nuevo debate en el que se vieron implicados los trenes y los automóviles. Así, mientras el transporte automotor ganaba importancia en el territorio y en la cultura de los argentinos, la infraestructura ferroviaria inició un paulatino declive, enfrentando una cruel disyuntiva, la de su perentoria refacción o la de su necesaria desaparición. Decadencia que se agravará, luego del Golpe de Estado de 1976, y concluirá en la solución privatizadora durante la década de 1990. 


\section{Referencias bibliográficas}

Ballent, A. (2005). "Kilómetro cero: la construcción del universo simbólico del camino en la Argentina de los años treinta". Boletín del Instituto de Historia Argentina y Americana "Dr. Emilio Ravignani”, 3(27), 107-137.

Bertuzzi, M. L. (2015). Marcas en el paisaje. Permanencias y ausencias como pautas de interpretación del territorio ribereño (Tesis doctoral). Universidad Politécnica de Catalunya. Barcelona, España.

Collado, A. (2012). "Introducción”. En A. Collado. (Comp.), El Corredor de la Costa. Conformación del paisaje y reconocimiento de sus recursos culturales, (pp. 7-24). Santa Fe, Argentina: Ediciones UNL.

Collado, A. \& Muller, L. (2012). El Puente Colgante. Historia, materia y símbolo. Rosario, Argentina: Aguas Provinciales de Santa Fe.

Martínez Estrada, E. (2001[1940]). La cabeza de Goliat. Microscopía de Buenos Aires. Buenos Aires, Argentina: Arte Gráfico Editorial Argentino.

Rausch, G. (2012). Territorialidad en la periferia urbana. La expansión de la ciudad sobre el valle de inundación, Santa Fe 1886-1959 (Tesis doctoral inédita). Universidad Nacional de Rosario, Rosario, Argentina.

Roccatagliata, J. A. (2008). "Las redes de transporte y la interacción espacial. Hacia un sistema intermodal y sustentable de transporte. Proyectos estratégicos". En J. A. Roccatagliata (Coord.), Argentina. Una visión actual y prospectiva desde la dimensión territorial, (pp. 285-322). Buenos Aires, Argentina: Emecé.

Romero, J. L. (2010[1956]). Las ideas políticas en argentina. Buenos Aires: Fondo de Cultura Económica.

Roverano, A. (1961). Santo Tomé. El paso histórico de Santa Fe de la Vera Cruz. Santa Fe, Argentina: Castellví S.A.

Seval, M.; De Rossi, L.; Del Turco, A. \& Pérez, M. (2016). "Consideraciones sobre la competencia de modos de transporte en la organización del territorio. El caso del municipio de Santa Fe de la Vera Cruz, Argentina". Entre Vistas, Revista de Debates, 7(8), 1-19.

Williams, F. (2004). “Arquitectura Ferroviaria”. En J.F. Liernur \& F. Aliata (Dir.), Diccionario de Arquitectura, tomo E-H, (pp. 76-87). Buenos Aires, Argentina: Arte Gráfico Editorial Argentino.

\section{Fuentes primarias (revistas, boletines y artículos periodísticos)}

El camino de la costa. (5/07/1911). Diario Santa Fe, p.1.

El camino a Santo Tomé (9/06/1912). Diario Santa Fe, p.2.

El camino de la costa. (22/06/1912). Diario Santa Fe, p.1.

El camino de la costa. (24/06/1913). Diario Santa Fe, p.1.

Las comunicaciones con Santo Tomé. (23/07/1915). Diario Santa Fe, p.2.

Continúa cortado el camino de la costa. (8/03/1922). Diario Santa Fe, p.1.

El camino de la costa. (4/10/1923). Diario Santa Fe, p.1.

Será reparado el camino de esta a Rincón. (9/02/1929). Diario El Orden, p.2. 
Se va a iniciar la pavimentación de la carretera Rosario - Santa Fe. (agosto de 1929). Revista del Puerto de Santa Fe, n 36, p. 20.

La intensificación del transporte por automotores mecánicos crea una situación incómoda a las empresas ferroviarias, la que debe ser contemplada por los poderes públicos. (mayo- junio de 1933). Revista del Puerto de Santa Fe, no 81-82, p. 3.

Las obras del camino a Santo Tomé. (7/12/1934). Diario El Litoral, p.4.

El nuevo puente debe ser construido de acuerdo a las necesidades de esta zona, fue lo convenido. (6/05/1935). Diario El Orden, p.2.

Estudiarán el nuevo puente. (16/02/1936). Diario El Orden, p.5.

Se dará comienzo a la construcción de una gran obra. El puente a Santo Tomé: Una realidad. (13/12/1936). Diario El Orden, p. 3.

Fueron presentados los planos del puente. (10/03/1937). Diario El Orden, p.5.

Nuevo Puente sobre el Río Salado. Comisión Pro Trazado Puente. (26/08/1937). Revista Santo Tomé, número único, pp. 13-14.

(junio-julio de 1940). Revista Técnica y Arte. Santa Fe: Asociación Técnicos Nacionales. Antes y después (1941). Boletín de la Dirección de Obras Públicas de la Provincia de Santa Fe, pp. 44-45.

El puente de más tránsito de la provincia es el de Santo Tomé (31/01/1942). Diario El Litoral, p.5.

Desaparecieron y esta vez para siempre, los famosos 7 puentes del antiguo camino carretero a Sto. Tomé (7/06/1950). Diario El Orden, p.8.

La vialidad nacional y provincial a través de 15 años de legislación vial (1948). Boletín de la Dirección General de Investigaciones, Estadísticas y Censos, nº 19, pp. 340-349.

La Ruta $\mathrm{N}^{\circ} 11$ en el Noroeste. (agosto de 1964). Revista Parabrisas, ${ }^{\circ} 45$, pp. 49-51.

La ciudad ideal: sin vías ferroviarias. (15/12/1967). Revista Tiempo, $\mathrm{n}^{\circ} 19$, p. 30.

Riesgo de aislamiento por falta de puentes a S. Tomé (20/02/1976). Diario El Litoral, p. 4. 